\title{
Crisis Response Strategy and Crisis Types Suitability: A Preliminary Study on MH370
}

\author{
Noratikah Mohamad Ashari ${ }^{1, *}$, Dayang Aizza Maisha Abang Ahmad ${ }^{1}$, and Mus Chairil \\ Samani ${ }^{1}$ \\ ${ }^{1}$ Department of Communication, Faculty of Language and Communication Studies, Universiti \\ Malaysia Sarawak, 94300 Kota Samarahan, Malaysia
}

\begin{abstract}
In time of crisis, the organisation's tactic in responding to the crisis according to its type/s may significantly affect the organisation's effort to survive its reputational damages. The study of crisis response strategy (CRS) requires further exploration within the Malaysian context, moreso with the greater and apparent use of social media as a platform for the organisation in crisis to reach out to its stakeholders. This preliminary paper studies the MH370 crisis in light of Coombs [1] Situational Crisis Communication Theory (SCCT). It aims to discuss the suitability of the CRS applied by Malaysia Airlines System (MAS) with the crisis type/s that was/were experienced by the organisation. Hence, the need for this paper to investigate the crisis type/s of MH370 and examines the CRS applied by MAS by content analysing media statements that were disseminated directly to the organisation's stakeholders on Facebook during the first day of the crisis. Results ultimately show an interesting analysis to the crisis type of MH370, and the suitability of the CRS applied by MAS for that matter.
\end{abstract}

\section{Introduction}

Crises implicate an organisation's reputation in ways that can lead to both economic and reputational challenges to the organisation. A sudden, unexpected crisis can damage or to great extent, lose the organisation's reputation if not managed carefully by the organisation in crisis. Regardless of the size, reputation or industry, there is always a possibility for every organisation to face any type of crisis situations.

This paper positions Situational Crisis Communication Theory (SCCT) [1] as the foundation of this study, particularly in regards to linking the crisis type and the application of crisis response strategies (CRS). At a glance, SCCT suggests that an organisation's reputation is a valued resource that is threatened by crises [2]. Moreover, SCCT functions to predict the reputational threat presented by a crisis and to prescribe CRS designed to protect reputational assets [1]. One can predict reputational threat with two steps [1]: (1) by assessing the initial crisis responsibility attached to a crisis (that is the crisis type) and then (2) assessing the other two intensifying factors of reputational threat - crisis history and prior relationship reputation. These crisis types, increased by factors of crisis history and

\footnotetext{
*Corresponding author: monaratikah@unimas.my
} 
prior relationship reputation, allow the organisation in crisis to indicate the crisis responsibility that is posed upon it and thus anticipate its stakeholders' perception and reaction towards the crisis and the organisation itself.

Responsibility requires accountability and therefore the organisation must answer for its action [3]. After a crisis strikes, it is crucial that the organisation in crisis responds to its stakeholders immediately. This is where crisis responsibility connects with CRS. CRS are what the organisation in crisis says and does after a crisis. They affect how stakeholders perceive the organisation as well as the crisis itself. Based on the stakeholders' perception, the organisation in crisis can determine which CRS is or are more suitable to protect its reputation. Hence, in order to repair the reputation, reduce negative affect, and prevent negative behavioural intentions [1], useful CRS are designed in SCCT relative to the crisis types. Past studies confirms that as CRS becomes more accommodative and show greater concern for victims, stakeholders perceive the organisation as taking greater responsibility for the crisis $[4,5]$. Therefore it is logical that organisations should initiate in preparing and establishing a successful CRS depending on the crisis type [1] to minimise the damage and scope of crises that are or will be faced upon.

The online environment through social media, websites, and even emails is one of the vital platforms used by many organisations to provide fast response to audiences in ways that is most appropriate to minimize damage and restore organisational reputation $[1,6]$ Plus, research indicates that a crisis website is deemed the best practice of internet usage during a crisis because it is another means for the organisation in crisis present its side of the story [7]. Apart from websites, the benefits of social media should not be ignored. CRS that are implemented through social media in disseminating information about the crisis to its key stakeholders is strategically important due to its efficiency, timely, and feedbackoriented nature. Social media present opportunities for organisations to tell its own account of a crisis without being subjected to journalistic gatekeepers and one-sided view of the crises as practiced in the press media [8]. In addition, social media are mostly used in sending cautions, to conduct situational wakefulness, and even to initiate actions [9]. Its networking abilities and the promise of a user-generated content therefore have made social media like Facebook an appropriate tool for resolving crisis communication. Despite its benefits, crisis communication in social media however provides organisations with little control of the audience response towards the response messages disseminated. Nevertheless, this points to the greater need for the organisation in crisis to strategise its response so that the CRS tallies with the crisis type that is faced upon.

\section{MH370: Malaysian Airline System (MAS) as an Organisation in Crisis}

There is still shortage of theoretical studies on orgnisational crises in the context of Malaysian organisations, despite the few notable organisational crises that can be reviewed for the study of crisis type and CRS suitability. Among Malaysia's most high profiled ones is the tragedy of Malaysia Airlines flight MH370. The tragic disappearance of Flight MH370 from Kuala Lumpur, Malaysia to Beijing, China with a total of 239 passengers and crewmembers had implicated the organisation with the utmost reputational threat in the history of its establishment. Conversely, the MH370 crisis had affected MAS stakeholders at such large scale, which includes the Malaysian government itself.

Coming from that, it is understandable that MH370 is fitting to the study of crisis types and CRS, given MH370 crisis is also well known and well speculated amongst various audiences at an international setting. Furthermore, as to the researchers' knowledge, there are no known empirical studies pertaining to the application of SCCT in a real organisation, especially in Malaysia. Although MAS is currently known as Malaysian Airline Berhad 
(MAB), the organisation in crisis is to be addressed as MAS rather than MAB, relevant to the timeline of the study particularly when MH370 crisis is concerned.

This study considers selecting the social media that is prominent in facilitating organisation's CRS. That is to determine the official social media page of the MAS. Only main pages directly established by the organisation will be used for the purpose of this study. As this study intends to examine how the organisation employs social media for CRS, pages established by stakeholders or third party users or unknown sources (eg. PrayForMH370) are not considered relevant for this study. During the crisis, MAS had responded to its stakeholders through various platforms from the start, Facebook namely one of them. On the first day of MH370, seven media statements were disseminated in MAS's official Facebook page. Due to the preliminary nature of this study, the scope is limited to the first day when the crisis occurred to eliminate the possibility of the crisis be influenced by other external factors such as news media reports, blogs, hearsay, and other opinions made by other parties. Thus, the scope of this study is strictly revolved within the contents of official media statements from MAS within 8th March 2014. The researchers justifies that the first day in which the crisis occurred is relevant in looking for the authenticity of how the organisation responds to the crisis to its stakeholders, as well as the organisation's initial control over information.

In that respect, the main aim of this study is to discuss the suitability between the crisis types and the CRS applied during a crisis as suggested in SCCT. This research analyses a total of seven media statements that were released on MAS official Facebook page on the day of the crisis, 8th March 2014 hence the population of the study. Using thematic content analysis [10] as a method of study by adapting Bales [11] in his analysis of conversation, this study refers that a single unit of analysis is considered as a single unit of attribute that will form a frame. The way these frames are formed help the researchers determine the type/s of crisis and CRS applied by MAS in its media statements. The researchers considers all forms of word/s and sentence/s as attributes to the framing that are consistent and relevant to the categories (the 12 crisis types and eight CRS) and the propositions of SCCT. The interpretation of the coding is based on the collective frequency count of each category (ie, for crisis types: victim cluster - rumours; for CRS: Primary - diminish - excuse) for all seven media statements.

This study is significant as it analyses an actual CRS that was disseminated by MAS to the public upon the mysterious disappearance of flight MH370 on the 8th March 2014. Moreover, this study somewhat brings light out of the mystery crisis by looking at which crisis cluster it falls into and as to whether or not SCCT potentially needs revisiting to suit the current crisis conditions in the age of new media.

\section{Identifying Crisis Types and Determining Suitable CRS}

SCCT suggests that the initial crisis assessment is based upon the crisis type. The crisis type is how the crisis is being framed. Frames include the way (words, phrases, images, etc) that information is presented in a message [12]. How stakeholders define problems, causes of problems, attributions of responsibility and solutions to problems are shaped by the way a message is framed [13]. The framing effect happens when the organisation chooses certain elements to focus on, which for the purpose of this study, are texts and attributes contained in the seven media statements. The stakeholders who receive the message will center their perception on those attributes while forming their opinions and making judgments towards the crisis [12]. Crisis types are a form of framing, in which each type highlights certain aspects of the crisis. These cues show how stakeholders ought to translate a crisis [2]. The organisation tries to develop or shape the crisis frame by focusing on certain cues or attributes to provide information as to what the causes of the crisis - 
whether the crisis is an accident, a force of nature, or intentional. It does make a difference if stakeholders see the crisis as a mishap, sabotage or criminal negligence because it determines the responsibility attributed to the organisation associated to the crisis by its stakeholders. There are 12 crisis types [2] identifed in which three crisis clusters are formulated based upon attributions of crisis responsibility [1] as shown and explained in Table 1.

Table 1. SCCT Crisis Types by Crisis Clusters (adopted from [1])

Victim cluster: In these crisis types, the organisation is also a victim of the crisis.

(Weak attributions of crisis responsibility $=$ Mild reputational threat)

Types: $\quad$ Natural disaster, Rumor, Workplace violence, Product Tampering/Malevolence

Accidental cluster: In these crisis types, the organisational actions leading to the crisis were unintentional.

(Minimal attributions of crisis responsibility $=$ Moderate reputational threat)

Types: $\quad$ Challenges, Technical-error accidents, Technical-error product harm

Preventable cluster: In these crisis types, the organisation knowingly placed people at risk, took inappropriate actions or violated a law/regulation.

(Strong attributions of crisis responsibility $=$ Severe reputational threat)

Types: $\quad$ Human-error accidents, Human-error product harm, Organisational misdeed with no injuries, Organisational misdeed management misconduct, Organisational misdeed with injuries

In this study, the crisis type is determined by analysing the attributes (word/s and sentence/s) that are relevant with the crisis types description, under the umbrella of the above three clusters.

Once the type of crisis or cluster is determined, the organisation in crisis can predict how much attribution will be placed on the organisation and how much reputational threat it is facing, and therefore, SCCT provides the organisation with a theoretical base to their CRS. Similar to the case of MH370, SCCT's list for responding to crises assumes that the organisation has accepted some level of responsibility for the crisis. The first type of CRS (primary) consists of three groups (denial, diminish, and rebuild) based upon perceptions of accepting responsibility for a crisis [1]. The secondary type of CRS (bolstering) functions as a supplemental strategy in too boost the organisation's existing reputation. The list is shown and defined in Table 2.

Table 2. SCCT Crisis Response Strategies (adopted from [1])

\begin{tabular}{|l|l|l|}
\hline \multicolumn{2}{|l|}{ Primary CRS } & \\
\hline \multicolumn{2}{|l|}{ Deny CRS } & Attack the accuser, Denial, Scapegoat \\
\hline & Diminish CRS & Excuse, Justification \\
\hline & Rebuild CRS & Compensation, Apology \\
\hline Secondary CRS & & \\
\hline & Bolstering CRS & Reminder, Ingratiation, Victimage \\
\hline
\end{tabular}

There are three objectives of CRS [1]: (1) to shape attributions of the crisis, (2) to change perceptions of the organisation in crisis, and (3) to reduce the negative effect generated by the crisis. In order to achieve such, the CRS must be at par with the attributed responsibility for the crisis - the crisis type or cluster. Each of the CRS assists the organisation in getting its side of the story into the media. Ultimately, the media's frames become the stakeholders' frames. For the purpose of this study, the media is MAS official Facebook page. A general guideline of suitable CRS is suggested [1] in order to suit each crisis cluster. The suitability can be adopted according to Table 3 . 
Table 3. SSCT Crisis Response Strategy Guidelines (adopted from [1])

\begin{tabular}{|c|l|}
\hline 1. & $\begin{array}{l}\text { Informing and adjusting information alone can be enough when crises have minimal attributions } \\
\text { of crisis responsibility (victim crises), no history of similar crises and a neutral or positive prior } \\
\text { relationship reputation. }\end{array}$ \\
\hline 2. & $\begin{array}{l}\text { Victimage can be used as part of the response for workplace violence, product tampering, natural } \\
\text { disasters and rumors. }\end{array}$ \\
\hline 3. & $\begin{array}{l}\text { Diminish crisis response strategies should be used for crises with minimal attributions of crisis } \\
\text { responsibility (victim crises) coupled with a history of similar crises and/or negative prior } \\
\text { relationship reputation. }\end{array}$ \\
\hline 4. & $\begin{array}{l}\text { Diminish crisis response strategies should be used for crises with low attributions of crisis } \\
\text { responsibility (accident crises), which have no history of similar crises, and a neutral or positive } \\
\text { prior relationship reputation. }\end{array}$ \\
\hline 5. & $\begin{array}{l}\text { Rebuild crisis response strategies should be used for crises with low attributions of crisis } \\
\text { responsibility (accident crises), coupled with a history of similar crises and/or negative prior } \\
\text { relationship reputation. }\end{array}$ \\
\hline 6. & $\begin{array}{l}\text { Rebuild crisis response strategies should be used for crises with strong attributions of crisis } \\
\text { responsibility (preventable crises) regardless of crisis history or prior relationship reputation. }\end{array}$ \\
\hline 7. & $\begin{array}{l}\text { The deny posture crisis response strategies should be used for rumor and challenge crises, when } \\
\text { possible. }\end{array}$ \\
\hline 8. & $\begin{array}{l}\text { Maintain consistency in crisis response strategies. Mixing deny crisis response strategies with } \\
\text { either the diminish or rebuild strategies will erode the effectiveness of the overall response. }\end{array}$ \\
\hline
\end{tabular}

\section{Results, Analysis and Discussion}

\subsection{Crisis Clusters and Types Experienced}

Based on timeline of this study, there were no mentions in the media statements as to the actual cause of the crisis. Therefore, the researchers interpret the contents of the media statements by analysing the framing cues that can help the researchers distinguish the type of crisis that MH370 fits into. Based on the result, MH370 interestingly belongs to all three crisis clusters (i.e. victim, accidental, and preventable).

The lowest count for type of crisis involving MH370 is in the victim cluster, specifically the Rumour type by two counts (i.e There has been speculation that the aircraft has landed at Nanming). Therefore, MAS did not emphasise that it is in a highly victimised crisis during the first day of the crisis. MH370 is also analysed as an accidental crisis. Herein, MH370 is framed as a Technical-error accident (i.e Malaysia Airlines confirms that flight MH370 has lost contact with Subang Air Traffic Control) due to the phrase "lost contact". This technical-error could consequently indicate what MH370 should have been if the flight has not lost contact with the air traffic control (i.e MH370 was expected to land in Beijing at 6.30am the same day). Accidental crisis also highlights the organisation's concerns on human lives, hence usually involves emergency plans (i.e We are working with authorities who have activated their Search and Rescue team to locate the aircraft). Under the same accidental cluster, there is only one count for Challenges type indicating that MAS has received stakeholders' claims about the lack of information given by MAS (i.e $W e$ understand/ everyone's concern/on MH370 pax \& crew).

As a preventable crisis, the statements repeatedly mention that the organisation itself is causing the incident (i.e ...that we have lost all contacts with flight MH370) by taking note of the word, "we". However, by placing the word "we" (Human-error accident) rather than "the flight has lost contact with Subang Air Traffic Control" (technical-error accident) as mentioned in the accidental cluster has made the framing inconsistent in explaining the cause and nature of the crisis. The most prominent frame in determining the crisis type of MH370 is the preventable crisis cluster by 44 counts, in which Organisational Misdeed 
without Injuries and Organisational Misdeed with Injuries analysed concurrently; therefore possess equal number of counts. The researchers interpret that the word/s or sentence/s that mentions the passengers and crews affected in the flight (i.e The flight was carrying a total number of 239 passengers and crew; 1. China - 152 plus 1 infant; 2. Malaysia - 38) in which stakeholders are put at risk either physically and/or psychologically by the organisation. It is challenging to determine as to whether or not there were any physical injuries involved within that timeframe, despite the organisation's repeated mentions of its regret towards the stakeholders (i.e Our thoughts/ and prayers/ are with all affected passengers/ and crew/ and their family members). On the other hand, the statements highlighting the effort in finding MH370 (i.e We are working with authorities/ who have activated their Search and Rescue team/ to locate the aircraft), thus indicate that the organisation has put these stakeholders at risk in terms of psychological and emotional uncertainty. Nevertheless, in the aspect of Organisational Misdeed without Injuries, it can be interpreted as such due to the lack of information or evidence that indicates that there were injuries occurring within that timeframe, hence a pretense to stakeholders in the organisation not being able to provide the actual cause of the crisis in the statement. In other words, the framing of the statements were overlapping and vague in describing the crisis type.

Therefore, the researchers find a loophole in the crisis type category of SCCT. Based on the crisis type framed in the statements, there is no accurate indication as to the physical human injuries of the stakeholders on board in MH370, although the organisation has listed down the detailed information of the affected passengers and crew. Because there is no accurate description in describing a crisis that is 'uncertain' in terms of actual physical human injuries, perhaps another crisis type that describes events that are as such can be added to the theory.

\subsection{CRS Applied and Suitability with Crisis Types}

The lowest count of CRS applied by MAS in regards to MH370 is the deny strategy, specifically Scapegoat strategy (i.e There has been speculation that the aircraft has landed at Nanming; We are working to verify/ the authenticity of the report and other.). Deny strategies seek to establish a crisis frame by attempting to remove any linkage between the organisation and the crisis [1]. This is to point that if MAS is not involved in a crisis, it will not suffer any damage from the event. Therefore, based on the Rumour and Challenge crisis types that are framed in the statement, this CRS applied is deemed suitable.

Result show that MAS utilises a large number of primary CRS, specifically the diminish strategy (Justification) for 55 times. Diminish crisis responses attempt to assure MAS stakeholders that MH370 crisis is not as bad as it seems or that MAS is not responsible for the crisis occurrence [1]. In the aspect of Excuse response strategy, MAS hints its inability to control the event by using the phrase "lost contact" (i.e Malaysia Airlines confirms/ that flight MH370 had lost contact/ with Subang Air Traffic Control at 2.40am, today). Furthermore, these strategies help lessen the connection between the MAS and the crisis and help MAS stakeholders see the crisis in a less negative light. In the media statements, MAS generally uses Justification to show its credibility and minimise negative impressions of the organisation. Credible evidence have been detected in the Justification strategy (i.e Flight MH370 was operated on a Boeing 777-200 aircraft; The flight was piloted by Captain Zaharie Ahmad Shah,/ a Malaysian aged 53./ He has a total flying hours of 18,365hours./ He joined Malaysia Airlines in 1981). On the grounds that MH370 being an accidental crisis and that MAS has never had such a crisis before, the diminish strategy applied is deemed suitable, as explained in Table 3, item no. 4. 
Rebuild strategies help alter perceptions of an organisation during a crisis [1] by offering real or symbolic forms of aid, that is Compensation (i.e The airline will provide regular updates on the situation) to victims and asking their forgiveness, that is a form of Apology (i.e We deeply regret/ that we have lost all contacts with flight MH370). These strategies attempt to take the focus off the crisis by taking positive action. Rebuild crisis response strategies should be used for crises with strong attributions of crisis responsibility (preventable crises) [1] regardless of crisis history or prior relationship reputation. In this study, although suitable in terms of technicality, the low count for rebuild strategies does not suit the high counts of preventable crisis type framing.

A secondary type of response, Bolstering is also used by only three counts in the media statements analysed, namely victimage in which MAS emphasises on triggering phrases that can make stakeholders sympathise with MAS by showing empathy towards the stakeholders at the same time (i.e We understand/ everyone's concern/ on MH370 pax \& crew./ We're accelerating/ every effort/ with all relevant authorities/ to locate the aircraft). True enough, this strategy does apply suitably with the Rumour and Challenge crisis types that $\mathrm{MH} 370$ is framed as mentioned earlier, and that it does supplement the primary responses in the media statements.

In the aspect of overall suitability of CRS according to the crisis type, findings indicate that the highest count for CRS applied (diminish strategies) is not suitable with the highest count of crisis type that is framed in the media statements (preventable cluster). If the CRS weighs more on primary CRS, particularly on diminish response therefore MH370 should be associated more with victim or accidental cluster [1]. The media statements have framed MH370 as a preventable cluster, and therefore should apply higher count for rebuild strategies, which comprises only a total of 15 counts compared to 58 counts for diminish strategies.

\section{Conclusion and Directions}

At a glance, result shows that MH370 is a crisis that comprises of all three crisis clusters, mainly preventable in nature. Based on the frames portrayed in the seven statements, the researchers identify attributes that make up the frame of all three crisis clusters. Nevertheless, analysis of the crisis types denotes that there is a loophole in describing a crisis that is 'uncertain' in terms of the cause of crisis. Given that it is a preliminary study in which the statements are content analysed according to textual lines (word/s and sentence/s) as separate frames, the cause of the crisis is yet to be determined as a major frame. As far as the researches' observation based on the findings, one can assume that as a major frame, the type of crisis for MH370 is considered 'uncertain'. This is due to the repetition of the phrase 'lost contact' as the main indicator in determining the type of crisis. SCCT has yet able to cover other possibilities of crisis types. In this case, the researchers propose two directions for future studies: 1) analysis of major message framing in MH370 CRS to determine its ultimate type of crisis based on an extended timeline of media statements; and 2) expand and examine another crisis type that is similar to MH370.

Also, this study finds that MAS utilises the diminish strategy most prominently as the CRS, mainly in terms of justification. As far as the suitability is concerned, the researchers see it as a complex relationship, in which the guidelines overlaps and lack in describing the suitability of each crisis type concerning the case of MH370. Results show that when MH370 is analysed based on its respective crisis type as a whole, every CRS applied is deemed suitable. However, when the crisis is analysed based on the count of attributes, the CRS applied is found to be not suitable. For instance, although MH370 was framed more as a preventable crisis, the CRS applied however is more inclined towards accidental or victim crisis. 
As far as the researchers' knowledge, past research regarding SCCT does not study the timeframe aspect as part of their consideration in applying the right CRS to the stakeholders. Taking into account the timeframe aspect will aid a depth to the current guidelines of CRS. Apart from the timeline, the messages and attributes framed in CRS could also further explore the overall tone and effectiveness of how the crisis is represented by the organisation. Since SCCT is rooted from Attribution Theory [1] that suggests stakeholders tend to search for the causes of events that are negative and unexpected [14, $15,3]$, stakeholders are also likely to react emotionally towards the event. Coming from that, this study can be expanded by analysing the message frames of the statements by looking at the statements' rational or emotional components (i.e information vs compassion). This can consequently bring light to the effects of CRS towards stakeholders' rational or emotional reactions. It is also proposed that the effects of CRS are studied by looking at the stakeholders' perspectives. This can be done by analysing comments by stakeholders in each of the statements disseminated by MAS, perhaps by examining the CRS effectiveness through the three objectives of CRS [1]: (1) shaping attributions to the crisis, (2) changing perceptions of the organisation in crisis, and (3) reducing the negative effect generated by the crisis, as indicators of effectiveness.

\section{References}

1. W. T. Coombs, CRR, 10, 163-176 (2007).

2. W. T. Coombs, S. J. Holladay, MCQ, 16, 165-186 (2006).

3. B. Weiner, Social Motivation, Justice, and the Moral Emotions: A Attributional Approach, (2006).

4. W. T. Coombs, S. J. Holladay, Responding to a Crisis: A Rhetorical Approach to Crisis Communication, (2004).

5. W. T. Coombs, S. J. Holladay, Research on Emotion in Organizations: Volume 1: The Effect of Affect in Organizational Settings, (2005).

6. A. Pang, APME, 23, 2 (2014).

7. M. Taylor, M. L. Kent, PRR, 33, 140-146 (2007).

8. B. F. Liu, Y. Jin, L. L Austin, JPRR, 25, 51-67 (2013).

9. S. Mukherjee, IJMIBS, 4, 2 (2014).

10. K. Krippendorff, Content Analysis: An Introduction to Its Methodology, (1980).

11. R. F. Bales. Content Analysis Reader (2009).

12. J. N. Druckman, PB, 23, 3 (2001).

13. A. H. Cooper, EJPR, 41, 37-80 (2002).

14. B. Weiner, PR, 92, 548-573, (1985).

15. B. Weiner, An Attributional Theory of Motivation and Emotion, (1986). 